\title{
Does cost sharing do more harm or more good? - a systematic literature review
}

Katarzyna Kolasa ${ }^{{ }^{*}}$ and Marta Kowalczyk ${ }^{2}$

\begin{abstract}
Background: There are positive and negative consequences of the implementation of out of pocket (OOP) payments as a source of the healthcare financing. On the one hand, OOP burden increases awareness of treatment costs and limits unnecessary use of healthcare services. On the other hand, it may prevent the sick from accessing needed care. Consequently there are several aspects that ought to be taken into consideration while defining the optimal structure of OOP payments. The objective of this study was twofold. Firstly, it was to understand what actions are taken to decrease the OOP burden. Secondly, it was to address the question whether the implementation of any form of formal OOP payments may impact negatively upon fairness in financial contribution.

Methods: The literature search was conducted using the Pubmed, Embase, Cochrane Library and Center of Review and Dissemination databases. Only studies which measured the Kakwani index of progressivity in at least two time points were included. Articles written in English published between January 2004 and September 2015 were searched. No geographical restriction was imposed. An increment of more than 0.10 in the Kakwani index was considered as a significant health policy impact.

Results: In total 16 publications were included, of which nine studied attempts to decrease the OOP burden, four described the consequences of the introduction of formal fees, and three covered both topics. Overall, a significant health policy impact was noted in four cases. All of them related to a reduction in the OOP burden, with three and one noting a change towards the progressivity and regressivity of direct healthcare payments respectively. Among jurisdictions which introduced formal fees, none study noted a significant impact on the regressivity of OOP spendings.

Conclusions: In the majority of cases, a health policy impact on the distribution of OOP health payments was insignificant. The reduction of OOP burden cannot be achieved successfully without adequate extension of healthcare coverage or engagement of other sources of healthcare financing. When formal fees are being introduced, protection against catastrophic healthcare payments is needed for the most vulnerable groups.
\end{abstract}

Keywords: Kakwani index, Progressivity, Out of pocket payments, Equity

\section{Background}

According to the World Health Organization there are three main goals for a healthcare system: good health, responsiveness to the expectations of the population, and fairness of financial contribution [1]. While the first objective, overall improvement of health, is self -explanatory the other two require more clarification. Responsiveness addresses the question of how far the healthcare system responds to people's expectations of it. The concept of

\footnotetext{
*Correspondence: kkolasa@wum.edu.pl

${ }^{1}$ Health Economics Department, Collegium Medicum Bydgoszcz,

Sandomierska 16, 85-630 Bydgoszcz, Poland

Full list of author information is available at the end of the article
}

fairness can be defined as "the highest possible degree of separation between contribution and utilization". It demands financial responsibility to vary according to ability to pay, and access to the healthcare system to vary according to healthcare needs irrespective of ability to pay [1].

According to the World Health Organization (WHO), all three of a healthcare system's ultimate goals should be considered equally valid. Improvement of health alone in society is not sufficient. In order to ensure a health system's responsiveness and financial protection, the consequences of the actions of health policy, especially with respect to the worst off, have to be 
thoroughly studied. Even a small absolute risk can be devastating to the health and financial situation of the poorest. Therefore unless the decision makers take into consideration the impact of their health policies on the least disadvantaged groups, all three healthcare system objectives cannot be successfully met. In an era of global crisis and decline in healthcare spending, the financial implications of healthcare policies upon the worst off carry an even stronger meaning [2].

Although the concept of financial protection refers to all sources of healthcare financing, out of pocket (OOP) health payments are of special importance. According to some experts, distribution of the OOP's burden across society should be considered "a strong test" of the fairness of the healthcare system [3].

When the public share of healthcare financing becomes insufficient, private healthcare expenditures have to compensate for it. If the balance between public and private funds is distorted, the health system objective of financial protection is undermined [4].

The available Organization for Economic Co-operation and Development (OECD) data indicates that OOP spending constitutes roughly $20 \%$ of total health expenditure [5]. The role of direct household healthcare payments goes beyond fiscal consideration. There are positive and negative consequences of cost sharing in the healthcare sector. On the one hand, direct participation of patients in healthcare financing increases awareness of treatment costs and limits unnecessary use of healthcare services. On the other hand, it may prevent the sick and disadvantaged from accessing the care needed [6]. Consequently, OOP health payments ought to be affordable for the worst off. Otherwise differences in access to medical services across society will become apparent and healthcare systems will fail to respond equally to everyone's needs.

The objective of this paper was to conduct a systematic literature review and investigate how different jurisdictions strive to achieve fairness in financial contribution with respect to OOP health payments. In particular it was to address two questions: What actions do health policy makers take to decrease the burden of OOP spending? Does the implementation of any form of formal user fees impact negatively upon fairness in financial contribution?

To allow comparisons between different time points as well as across jurisdictions, studies which calculated the Kakwani index were selected [7]. The Kakwani Index is the most widely used measure of fairness in financial contributions in the healthcare sector. It addresses the question of how the distribution of OOP health payments departs from proportionality. Equity according to need requires that everyone is entitled to access the healthcare system irrespective of the size of their financial resources. It can only be achieved if healthcare contributions are collected according to the principle of ability to pay. Hence the underlying hypothesis for this study was that for the healthcare system to pursue the objective of fairness in financial contributions it needs to ensure the financial burden is distributed progressively or at least proportionally.

\section{Methods}

The literature search was conducted using the Pubmed, Embase, Cochrane Library and Center of Review and Dissemination databases. The following key words were used: out-of-pocket payments, health expenditures, cost sharing, deductibles, coinsurance and copayments. Each of them was paired with two search words: Kakwani Index and progressivity. In order to address the research questions, studies which measured the Kakwani index of progressivity in at least two time points were included. All articles written in English and published between January 2004 and September 2015 were searched. No geographical restrictions were imposed. Publications limited to the methodological considerations and disease specific studies were excluded.

The systematic review was conducted and reported according to the Preferred Reporting Items for Systematic Reviews and Meta-Analyses (PRISMA) checklist [8]. Selection and review of papers was conducted independently by two reviewers, and disagreements were resolved by consensus.

The following subgroups were constituted for the purpose of the analysis: studies of health policy actions to decrease the burden of OOPs, studies of the consequences of the introduction of a formal system of OOPs, and those which covered both topics. A review of legal changes (health policy impact) during the period studied was conducted to classify each publication into one of the above groups.

The Kakwani index measures the degree to which the distribution of out of pocket payments departs from proportionality. It is calculated as the difference between the Concentration index (C) and the Gini coefficient (G) [7].

$$
k=C-G
$$

While the first measures the degree of income-related inequality of a given health variable (in our case OOP payments), the second assesses income inequality. The Kakwani index can take values from minus two to one. Because the concentration index takes a value from minus one to one (when all OOP payments are borne by the poorest and riches person respectively. Whereas the Gini coefficient varies from zero (perfect income equality) to one (perfect income inequality). A positive value of the Kakwani index indicates progressivity. A negative value, on the other hand, means regressivity. If the index 
equals minus two, the concentration of pre-payment income occurs at the very top of the distribution and the poorest person bears all of the OOP spending. When the Kakwani index equals one, the pre-payment income is distributed equally and all of the OOP payments are borne by the richest person. If, by contrast, direct healthcare expenditures are a proportional source of healthcare financing, the Kakwani index will be zero.

In a graphical way, the Kakwani index can be defined as twice the area between a Lorenz curve and a concentration curve. The Lorenz curve represents income distribution. It plots the cumulative proportion of income against the cumulative proportion of the population ranked according to the income. The more unequal the distribution the further the Lorenz curve lies below the diagonal (the line of perfect equity). The concentration curve represents health variable distribution (such as OOP burden). It plots the cumulative percentage of OOP payments against the cumulative percentage of the population, ranked by income. If OOP expenses are disproportionally distributed amongst poorer (richer) people, the concentration curve will lie above (below) the line of equality. If $\mathrm{OOP}$ payments are a progressive (regressive) source of financing, the concentration curve will lie below (above) the Lorenz curve, and the Kakwani index will be positive (negative).

The significance of the change was measured following the approach introduced by Yu et al. (2008). They assumed that an increment in the index of more than 0.10 was considered as significant [9].

Studies of equity in healthcare financing allow for different measurements of ability to pay to be used. Disposable household income or household expenditures are used interchangeably. There are pros and cons for both measurements. Given the potential impact of the choice of ability to pay measurement on results, it was reported separately for each study.

\section{Results}

In total 77 publications which fulfilled the criteria, based on screening of the title, were identified in the databases. As many as 70 were excluded during the abstract review process out of which 37 were repetitions, 17 only reported the Kakwani index for 1 year of observation, five were limited to methodological considerations and seven did not report the Kakwani index at all. Additionally, there were three with limited scope of analysis to a specific group of patients and one was excluded due to non-English language. The remaining seven were selected for the review. A subsequent search of references and grey literature revealed an additional nine studies.

In total, 16 publications were included. Figure 1 shows the flow diagram of selection of publications.

Table 1 provides the basic characteristics of all reviewed studies. While eight publications reported income, only seven studies used expenditure as a welfare measurement. In one case, both approaches were tested.

Except for the article written by Hanley et al. regarding British Columbia in Canada, all studies utilized household surveys for the purpose of the analysis. In contrast to the others, the Canadian study was based on a prescriptions' database. The size of study population varied from 1600 households in Slovakia to 1,700,000 households in British Columbia in Canada [10, 11].

Following the approach outlined in the methodology, studies were categorized into three groups. The first

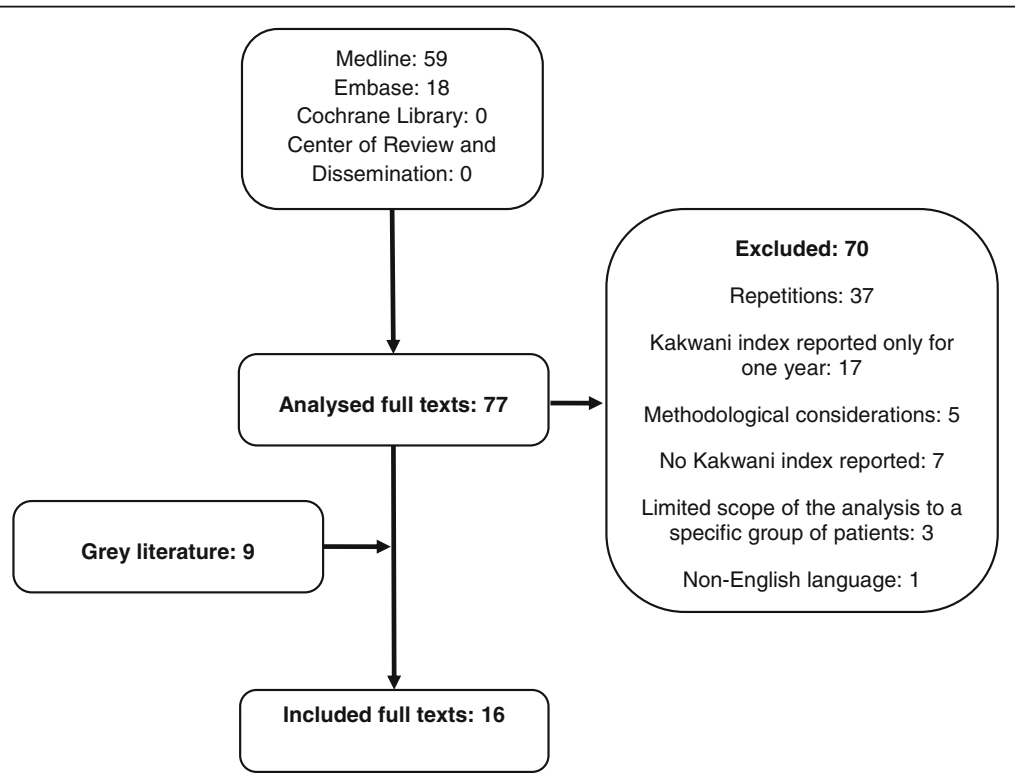

Fig. 1 The systematic review flow 
Table 1 List of studies included in the systematic review

\begin{tabular}{|c|c|c|c|c|c|}
\hline Author & Jurisdiction & $\begin{array}{l}\text { Year of } \\
\text { publication }\end{array}$ & Data source & No of households (year) & Reference \\
\hline 1 Markova N. & Bulgaria & 2006 & $\begin{array}{l}\text { Living Standards Measurement } \\
\text { Surveys (LSMS) of the World } \\
\text { Bank for } 1995 \text { and } 2001\end{array}$ & 2400 (Y 1995-2001) & [23] \\
\hline 2 Hanley G. E.et al. & $\begin{array}{l}\text { Canada/British } \\
\text { Columbia }\end{array}$ & 2008 & $\begin{array}{l}\text { BC PharmaNet, prescription drug } \\
\text { utilization data for residents } \\
\text { registered for BC Medical Services } \\
\text { Plan for at least } 275 \text { days during } \\
\text { each year from } 2000 \text { to 2004) }\end{array}$ & $1,700,000(Y$ 2000-2004) & [10] \\
\hline 3 Chen M., Zhao Y., Si L. & China & 2014 & $\begin{array}{l}\text { Household Surveys, Heilongjiang } \\
\text { province, Northeast China }\end{array}$ & 3841 (Y 2003); 5530 (Y 2008) & {$[17]$} \\
\hline 4 Chen M. Chen W. Zhao Y. & China & 2012 & $\begin{array}{l}\text { Household Surveys, Gansu province, } \\
\text { China. }\end{array}$ & 3946 (Y 2003); 3958 (Y 2008) & [18] \\
\hline 5 Castano R. et al. & Columbia & 2002 & $\begin{array}{l}\text { Nation-wide cross sectional surveys, } \\
\text { the National Department of } \\
\text { Statistics (DANE). }\end{array}$ & $\begin{array}{l}26,117 \text { (Y 1984); 28,022 (Y 1994); } \\
9121 \text { ( }(1997) .\end{array}$ & [14] \\
\hline 6 Krutilova V. & Czech Rep & 2013 & $\begin{array}{l}\text { Household Budget Survey (HBS), } \\
\text { Survey on Income and Living } \\
\text { Conditions (SILC) and European } \\
\text { Health Interview Survey (EHIS) }\end{array}$ & $\begin{array}{l}2765 \text { (Y 2007); } 2685 \text { (Y 2008); } \\
2686 \text { (Y 2009) }\end{array}$ & [22] \\
\hline 7 Võrk A., Saluse J., Habicht J. & Estonia & 2009 & Estonian Household Budget Surveys & 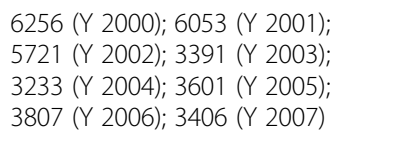 & {$[20]$} \\
\hline 8 Dukhan $Y$ et al. & France & 2010 & $\begin{array}{l}\text { French household budget surveys } \\
\text { from 1995, } 2001 \text { and } 2006\end{array}$ & $\begin{array}{l}10,240(2006) ; 10,305 \text { (2001); } \\
9634(1995)\end{array}$ & [25] \\
\hline 9 Baji P. et al. & Hungary & 2012 & $\begin{array}{l}\text { Household Budget Survey, the } \\
\text { Central Statistical Office }\end{array}$ & $\begin{array}{l}9058 \text { (Y 2005); } 8975 \text { (Y 2006); } \\
8547 \text { (Y 2007); } 7650 \text { ( Y 2008) }\end{array}$ & {$[21]$} \\
\hline 10 Zare H. et al. & Iran & 2014 & $\begin{array}{l}\text { Iran's Households Income and } \\
\text { Expenditure Survey (HIES), the } \\
\text { Statistical Center of Iran (SCI) }\end{array}$ & $\begin{array}{l}342,532 \text { rural; 308,735 urban } \\
\text { (Y } 1984 \text { - Y 2010) }\end{array}$ & [19] \\
\hline 11 Smith S. & Ireland & 2010 & $\begin{array}{l}\text { Household Budget Survey (HBS) } \\
\text { data for 1987/88,13 1999/2000 } \\
\text { and 2004/05. }\end{array}$ & $\begin{array}{l}7705 \text { (Y 1987/88); } 7644 \\
\text { (Y 1999/2000); } 6884 \text { (Y 2004/05) }\end{array}$ & {$[24]$} \\
\hline 12 Kiss S. & Slovakia & 2007 & $\begin{array}{l}\text { Household Budged Survey, the } \\
\text { Statistical Office for 2001-2005 } \\
\text { of the Slovak Republic }\end{array}$ & 1600 (Y 2001-2005) & [11] \\
\hline 13 Limwattananon S. et al. & Thailand & 2011 & $\begin{array}{l}\text { Health and Welfare Surveys (HWS) } \\
\text { household surveys conducted by } \\
\text { the National Statistical Office in } \\
2001,2003,2006 \text { and } 2007\end{array}$ & 70,000 individuals (Y 2001 - Y 2007) & [12] \\
\hline 14 Ali SI & Vietnam & 2009 & $\begin{array}{l}\text { Cross-sectional household survey } \\
\text { data collected from three provinces: } \\
\text { Hai Phong, NinhBinh and Dong Thap }\end{array}$ & $\begin{array}{l}1650 \text { adults; } 1101 \text { children } \\
\text { (Y 1999) }\end{array}$ & [13] \\
\hline 15 ÖzlemGöçmez & Turkey & 2010 & $\begin{array}{l}\text { "Household Budget Survey" from } \\
\text { Turkish Statistical Institute for } \\
\text { years } 2003 \text { and } 2006\end{array}$ & $\begin{array}{l}\text { 2003- } 25,920 \text { households, } \\
2006-8640 \text { households }\end{array}$ & {$[15]$} \\
\hline $\begin{array}{l}16 \text { Yardim M.S. Cilingiroglu N. } \\
\text { Yardim N. }\end{array}$ & Turkey & 2014 & $\begin{array}{l}\text { "Household Budget Survey" from } \\
\text { Turkish Statistical Institute for years } \\
2003 \text { and } 2006 \text { and } 2009\end{array}$ & $\begin{array}{l}\text { 2003-25,920 households, } \\
2006-8640 \text { households, } \\
2009-12,600 \text { households }\end{array}$ & [16] \\
\hline
\end{tabular}

one consisted of publications which analyzed health policies' attempts to decrease the OOP burden. Out of nine studies included in this group, seven focused on the impact of the introduction of universal healthcare coverage, one analyzed the implementation of voluntary healthcare insurance and the last one evaluated the consequences of changes in drug policies (Table 2). The second group consisted of four studies which described the impact of the introduction of OOP health payment regulations on fairness in financial contribution. They covered health policies embracing formal fees for both ambulatory care visits and hospital stays, as well as 
Table 2 The description of health policies aiming at OOP burden reduction

\begin{tabular}{|c|c|c|c|c|}
\hline \multirow[t]{2}{*}{ Jurisdiction } & \multirow{2}{*}{$\begin{array}{l}\text { Health policy objective in the } \\
\text { studied period }\end{array}$} & \multicolumn{2}{|l|}{ Cost sharing mechanism } & \multirow[t]{2}{*}{ Reference } \\
\hline & & Outpatient/Inpatient services & Pharmaceuticals & \\
\hline 1 Canada & $\begin{array}{l}\text { Decrease the OOP burden } \\
\text { regarding pharmaceutical } \\
\text { spending for least } \\
\text { disadvantaged }\end{array}$ & NA & $\begin{array}{l}\text { Shift from age-based to income- } \\
\text { based eligibility drug reimbursement } \\
\text { system: } 1 \text {. before 2002; } 100 \% \text { drug } \\
\text { coverage for social assistance } \\
\text { recipients, } 100 \% \text { coverage with } \\
\text { pharmacists' dispensing fees for } \\
\text { seniors and fixed-deductible } \\
\text { coverage for 'catastrophic' drug } \\
\text { expenses for others } 2 \text {. In 2002; } \\
\text { prescription fees for seniors with } \\
\text { cap on spending, others remained } \\
\text { unchanged } 3 \text {. from } 2003 \text {; three } \\
\text { age-income groups, co-insurance } \\
\text { varies from } 0 \text { to } 30 \% \text {, family } \\
\text { deductibles- from } 0 \text { to } 3 \% \text { of } \\
\text { household gross income, max } \\
\text { OOPs- from } 0 \text { to } 4 \% \text { of } \\
\text { household gross income }\end{array}$ & [10] \\
\hline 2 China & Decrease the OOP burden & There are two types of healthcare & NA & {$[17,18]$} \\
\hline
\end{tabular}
after the introduction of insurance based healthcare system.

3 Columbia Decrease the OOP burden after the introduction of insurance based healthcare system.

4 Iran

Decrease the OOP burden after the introduction of insurance based healthcare system.

5 Thailand The extension of universal healthcare coverage insurance for city dwellers. Urban Resident's Basic Medical Insurance (UWBMI) for employees and Urban Resident's Basic Medical Insurance (URBMI) for the unemployed, children, students, and elderly persons without pensions were introduced. In the UWBMI, employees and employers contribute $2 \%$ and $6-8 \%$ of salaries respectively. The URBMI is funded by individuals with appropriate subsidies granted by government. In $2003 \mathrm{New}$ Rural Cooperative Medical Scheme (NCMS) for rural workers were established (92\% coverage in 2007).

In 1993 National Social Health Insurance System (NSHIS) was established: 1. Employed and selfemployed were financed solidarly by employees and employers (in total $12 \%$ of salary). It covered all first-degree family members of those who contribute and pensioners. 2. Poor were financed by taxes and solidarity contribution from other insurance funds. The poor was defined by set of criteria such as labor market participation, income, educational attainment, family structure, access to water and sanitation and others. Interventions are grouped by categories of medical care and levels of complexity.

Healthcare reform steps: 1. development of primary health care $(\mathrm{PHC})$ networks and medical facilities (1990-94), 2. the introduction of health insurance (1994-99) 3. Further development and improvement of healthcare coverage (2000-04), 4. decreasing inequalities in health expenditures (2005-09)

Since October 2001, Universal health insurance system: the curative package (ambulatory and hospitalization service), the high-cost care package, and the promotive and preventive package. The $B$ 30 copayment was introduced in 2001
In 2003 a universal access to 
Table 2 The description of health policies aiming at OOP burden reduction (Continued)

\begin{tabular}{|c|c|c|c|c|}
\hline & & $\begin{array}{l}\text { (equivalent to US\$ } 1 \text { in 2010) per } \\
\text { ambulatory visit or hospital admission. It } \\
\text { was abolished in } 2006 \text {. The total number of } \\
\text { insured rose from } 33 \% \text { in } 1991 \text { to } 71 \% \text { in } \\
2001 \text { and } 98 \% \text { in } 2007 . \text { In } 2007 \text {, the } \\
\text { universal coverage was the biggest insurer } \\
\text { (75\% of total population), Social Security } \\
\text { Scheme for private employees (13\%), Civil } \\
\text { servants for public employees (8\%) private } \\
\text { health insurance (2\%). }\end{array}$ & & \\
\hline 6 Turkey & $\begin{array}{l}\text { Extension of free of charge } \\
\text { healthcare for low income } \\
\text { inhabitants (green card holders) }\end{array}$ & $\begin{array}{l}\text { In } 1992 \text { a Green card system was established } \\
\text { for income below one-third of the base } \\
\text { wage rate (ca } 18 \% \text { of population in 2007). It } \\
\text { allowed a free access to inpatient care. In } \\
2004 \text { it was extended to cover alllevels of } \\
\text { healthcare except for } 20 \% \text { co-payment for } \\
\text { pharmaceuticals. One year later, Green Card } \\
\text { holders were given access to outpatient care } \\
\text { and pharmaceuticals. In } 2008 \text {, they have } \\
\text { formally joined Universal Health Insurance. } \\
\text { By } 2011 \text {, about } 85 \% \text { of the poorest decile } \\
\text { was covered by the Green Card or another } \\
\text { insurance scheme. } \\
\text { Non-Green card holders pay } 8 \text { TL (€3.6) } \\
\text { and } 15 \text { TL (€6.8) for outpatient services in } \\
\text { public and private hospitals, respectively } \\
\text { unless they have referral from a GP. } \\
\text { Primary care services are free of charge. } \\
\text { After } 2003 \text {, additional copays may apply if } \\
\text { the cost of care in a private hospital is } \\
\text { higher than public reimbursement. } \\
\text { Informal payments are estimated at } 5.2 \% \\
\text { of total OOP expenditure. }\end{array}$ & $\begin{array}{l}20 \% \text { of prescription charges for } \\
\text { all active workers including Green } \\
\text { Card holders; retirees pay } 10 \% \text {. } \\
\text { Since } 2004,333 \text { jumbo referencing } \\
\text { groups established. A reimbursement } \\
\text { for any product set at the level of the } \\
\text { cheapest in the group plus } 15 \% \text {. } \\
\text { Patient pays the difference between } \\
\text { reimbursement and the actual } \\
\text { price of the drug. }\end{array}$ & {$[15,16,38,39]$} \\
\hline 7 Vietnam & $\begin{array}{l}\text { The role of Voluntary Health } \\
\text { Insurance in broadening the } \\
\text { access to healthcare system }\end{array}$ & $\begin{array}{l}\text { Since 1991, healthcare services were } \\
\text { covered mainly through OOPs. After } \\
\text { healthcare reform in 1992, three groups of } \\
\text { beneficiers were established: 1.eligible for } \\
\text { Compulsory Health Insurance (public } \\
\text { sector, workers of private companies } \\
\text { companies with over ten employees) } 2 . \\
\text { eligible for Voluntary Health Insurance } \\
\text { (employed not included in 1, self- } \\
\text { employed, dependend of those in group 1, } \\
\text { school children and other students) 3. Not } \\
\text { eligible for Compulsory Health Insurance } \\
\text { and too poor for VHI. Out of } 76 \text { mln of } \\
\text { Vietnamese in the group 2, } 3.6 \text { mln had } \\
\text { VHI and } 33.4 \text { mln still paid fully OOPs. Since } \\
1998, \text { insured patients are obliged to make } \\
\text { a copayment of } 20 \% \text { of the total costs of } \\
\text { care provided. An annual ceiling of half the } \\
\text { minimum annual salary was introduced } \\
\text { as well. }\end{array}$ & NA & [13] \\
\hline
\end{tabular}

copayments for drugs (Table 3). Finally the third group gathered the remaining three studies which covered both the implementation of public and private healthcare insurance as well as the introduction of formal fees for healthcare visits (Table 4).

Out of the nine publications included in the first group, three reported significant improvement in progressively of OOP payment distribution measured by the Kakwani index during the study period (Table 5). This was the case for British Columbia in Canada, Thailand and Vietnam $[10,12,13]$. The first one differed from the others by the fact that OOP spending was the most regressive source of healthcare financing at baseline i.e. before the reform took place. Although only limited to the drug policy, it was the largest and most significant reduction of regressivity across all of the studies reviewed. In Thailand, the introduction of a universal health insurance system lead to significant improvement of the Kakwani index [12]. Conditional on the methodological approach taken, the Vietnamese study indicated 
Table 3 The description of consequences of OOP healthcare payments' introduction

\begin{tabular}{|c|c|c|}
\hline \multirow[t]{2}{*}{ Jurisdiction } & \multirow{2}{*}{$\begin{array}{l}\text { Health policy change in } \\
\text { studied period }\end{array}$} & Cost sharing mechanism \\
\hline & & Outpatient/Inpatient services \\
\hline 1 Czech Rep & Introduction of formal fees & $\begin{array}{l}\text { Until the end of 2007, outpatient and } \\
\text { inpatient services were free of charge. } \\
\text { Since 2008, formal OOPs exists; a flat fee of } \\
30 \text { CZK ( } € 1.2) \text { per doctor visit, } 60 \text { CZK ( } € 2.4) \\
\text { per hospital day as well as spa hotels, } 90 \\
\text { CZK ( } € 3.6) \text { per ambulatory visit outside of } \\
\text { working hours. An annual ceiling of CZK } \\
5000 \text { ( } € 200) \text { for expenses related to doctor } \\
\text { visits and drug costs was introduced. Since } \\
2009 \text {, a new ceiling of CZK } 2500 \text { ( } € 100) \text { for } \\
\text { those below } 18 \text { and above } 65 \text { was } \\
\text { launched. A flat fee per doctor visit for } \\
\text { children was eliminated. Since } 2012 \text {, a flat } \\
\text { fee for hospital and spa stay was reduced } \\
\text { to } 100 \text { CZK per stay ( } € 3.92 \text { EUR). The dental } \\
\text { care is paid by OOPs too. Some groups } \\
\text { such as poor, pregnant woman, chronically } \\
\text { ill children, patients with infectious } \\
\text { diseases are exempted from formal OOPs. } \\
\text { (Exchange rate used; } 1 \text { EUR }=250 \text { CZK) }\end{array}$ \\
\hline
\end{tabular}

2 Estonia Introduction of formal fees since 1995, a fee of $€ 0.30$ (EEK 5) per first initial outpatient consultation at public hospitals and/or health centers exists, a free price setting for specialists. Since 2002, no fees for GP visits (except for home GP visit which is €3.2) but ambulatory specialist care at maximum fee of $€ 3.20$ (EEK 50) unless a referral within the same institution or specialty is granted. Hospital fees are implemented at 1.6 EUR per day, for up to 10 days per episode of illness. Some exemptions for children, pregnant woman and emergency care apply. (Exchange rate used; $1 \mathrm{EUR}=15.6 \mathrm{EEK}$ )

3 Hungary Introduction of formal fees To limited extend, some form of copayments already existed since 1989 (medical devices, spas, specialist treatment outside of standard patient's pathway etc.). Since 2007 formal co-payments were introduced; app $€ 1$ per ambulatory visit and per hospital day. After the referendum held in 2008, they were abolished.
4 Slovakia Introduction of formal fees
The formal copayments were introduced in 2003. Since then, app. €0.66 is paid per doctor visit and app. 1.66 EUR per hospital day, app €1.99 per emergency care visit, $€ 0.07$ per $\mathrm{km}$ for ambulance transport and between $€ 4.98$ and 7.30 per food and accommodation in spas. In 2006, user fees for a doctor's visit and daily hospital stay were abolished. (Exchange rate used; 1 $\mathrm{EUR}=40.03 \mathrm{SKK}$ )
Co-payment consist of a prescription fee of $€ 1.30$ plus the difference between actual price and reimbursement level. The general reimbursement rate is $50 \%$ of the pharmaceutical price up to a maximum reimbursement of $€ 12.00$ (EEK 200) per prescription. The reimbursement of drugs for chronic disease, children, seniors and disabled is higher, up to $100 \%$.

Since 2007 reimbursement rates have been decreased from 50 to $25 \%$; from 70 to $55 \%$; and from 90 to $85 \%$. For drugs with a special reimbursement of $90 \%$, three levels of coverage was established: 50,70 and $90 \%$. For drugs fully reimbursed, a minimum $€ 1$ (300 HUF) fee per prescription was introduced. For special attentionpatients eligible for free of charge drugs, a monthly limit of 40 EUR was established. OOPs apply above that sum. Eligibility for special attention is defined by GP. (Exchange rate used; $1 \mathrm{EUR}=250 \mathrm{HUF}$ )

Until 2003, some form of co-payments existed. Since then $€ 0.5$ EUR prescription fee has to be paid. It was reduced to $€ 0.17$ in 2006. If there is a difference between the price of the drug and the reimbursement level, patient has to cover it as well.

burden. Among them were studies regarding Columbia,

that voluntary healthcare insurance (VHI) significantly improved the progressivity of OOP payments compared to non-VHI healthcare users as well [13].

Apart from one, the remaining publications in the first group did not report any significant decrease of OOP
Turkey, China and Iran [14-19]. While the Kakwani index improved slightly for Columbia, the opposite was found for Turkey. Despite minor differences in the methodological approach towards the calculation of the income 
Table 4 The description of health policies aiming both OOP healthcare payments' introduction and at OOP burden reduction

\begin{tabular}{|c|c|c|}
\hline \multirow[t]{2}{*}{ Jurisdiction } & \multirow{2}{*}{$\begin{array}{l}\text { Health policy change in } \\
\text { studied period }\end{array}$} & Cost sharing mechanism \\
\hline & & Outpatient/Inpatient services \\
\hline 1 Bulgaria & $\begin{array}{l}\text { 1. Introduction of universal } \\
\text { healthcare insurance system } \\
\text { 2. Implementation of formal fees }\end{array}$ & $\begin{array}{l}\text { The healthcare insurance act of } 1998 \\
\text { converted the Bulgarian health system } \\
\text { into a health insurance system. Since } \\
2000 \text { formal co-payments at } 1 \% \text { of the } \\
\text { minimum wage for GP and outpatient } \\
\text { visit, } 2 \% \text { of the minimum wage for the } \\
\text { first } 10 \text { days of the hospital stay (no fee } \\
\text { for a subsequent hospitalization during } \\
\text { the year), emergency care without co-pays, } \\
\text { full price for specialist care and other } \\
\text { services outside the standard patient } \\
\text { pathway. User fees apply to all patients with } \\
\text { some exceptions: children, pregnant women, } \\
\text { unemployed individuals, those with income } \\
\text { below a certain threshold, chronically sick } \\
\text { patients and some other groups. }\end{array}$ \\
\hline
\end{tabular}

2 France 1. Introduction of public complementary health insurance coverage for certain groups introduced 2. Implementation of formal fees
3 Ireland 1. The expansion of GP Visit Card accessibility 2. A decline of 95,000 in the number of Medical Card holders (1997-2005)
In general, healthcare insurance coverage varies from $100 \%$ for hospital care to $70 \%$ for ambulatory care and $60 \%$ for medical auxiliaries as well as for laboratory tests. Full coverage exists for long-term illnesses, pregnant woman (after 5th month) and others. A system of copayments; since 2004, an extra co-payment for direct access to specialists or other GPs without remission (40\% of the standard $\mathrm{SHI}$ tariff). a flat-rate catering fee of $€ 18$ per day for accommodation in hospital. Since 2005, €1 on every physician visit, biological test and radiograph up to a ceiling of $€ 4$ per day and $€ 50$ per year has been introduced. Since 2006, patients have had to pay a flat rate of $€ 18$ for care with a statutory tariff over €91. VHI covers cost sharing without flat fees (other exemptions apply as well). The VHI population's coverage increased from $50 \%$ in 1970 to $88 \%$ in 2006. A free public complementary health insurance $(\mathrm{CMU})$ and a voucher scheme (ACS) for those who cannot afford VHI were established in 2000 and 2004 respectively.

For medical card holders (eligibility is set based on income and age) there is a free of charge GP, hospital and dental care, drugs, medical appliances and others. Non-medical card holders pay out of pocket for GP visits (from $€ 50$ to $€ 90$ ), consultants' fees, €66 for hospital stay per day up to $€ 660$ per year. Based on a referral for inpatient and outpatient services, no charges are levied for diagnostic tests. Private health insurance covers fully OOPs for inpatient care and outpatient services to some extent. The costs of dental and optical care is reduced for Treatment Benefit Scheme holders (operated by the Department of Social and Family Affairs for those who pays Pay-related social insurance). The number of medical cardholders decreased from $37 \%$ in 80 -ties to $30 \%$ in 2007. Since 2005, for those with income up to $50 \%$ (change from $25 \%$ ) higher than the ceiling for a Medical Card, a free of charge GP visits' system (GP Visit Card) was introduced. The evolution of private health insurance from $4 \%$ - 1960 to $35 \%$-1987
Reimbursement rates varies from $15,35,65$ or $100 \%$. On the average rate of reimbursement for drugs is estimated to be $73 \%$. There is a fee of $€ 0.5$ is charged for every drug package up to a ceiling of $€ 50$ per year .
References

[29]

shortlist full coverage for outpatient, inpatient settings as well as treatment for oncological, rare, infectious diseases as well as AIDS. Drugs outside Positive List have to be fully paid out of pocket.

For medical card holders - free of charge, for others - up to $€ 90$ per month. For chronic long-Term Illness Scheme, open to individuals with one of a number of predefined chronic conditions - covers the costs of all necessary pharmaceuticals, medicines and appliances Others bears full cost of the drug but they should apply for a Drugs Payment Scheme (DPS) which limits out-of-pocket expenditure for an individual or family to no more than certain ceiling (for example in 2014; €144) per calendar month for prescribed pharmaceuticals, medicines and appliances. DPS replaced Drugs Refund Scheme in July 1999. DRS operated on similar principles as DPS. 
Table 5 Kakwani index of progressivity in selected publications

\begin{tabular}{|c|c|c|c|c|c|c|c|c|c|}
\hline & & \multirow[t]{2}{*}{ Group } & \multirow[b]{2}{*}{ Year } & \multicolumn{3}{|l|}{ Kakwani index } & \multicolumn{2}{|l|}{ Ability to pay } & \multirow[t]{2}{*}{ Reference } \\
\hline & & & & $\overline{\mathrm{OOP}}$ & $\begin{array}{l}\text { Private health } \\
\text { insurance }\end{array}$ & $\begin{array}{l}\text { Total healthcare } \\
\text { financing }\end{array}$ & $\begin{array}{l}\text { Household } \\
\text { expenditures }\end{array}$ & $\begin{array}{l}\text { Disposable } \\
\text { income }\end{array}$ & \\
\hline \multirow[t]{5}{*}{1} & \multirow[t]{5}{*}{ Canada } & \multirow[t]{5}{*}{1} & 2001 (non seniors) & -0.373 & -0.100 & & & $x$ & [10] \\
\hline & & & 2001 (seniors) & -0.299 & NA & & & & \\
\hline & & & 2004 (non seniors) & -0.253 & & & & & \\
\hline & & & 2004 (seniors) & -0.078 & & & & & \\
\hline & & & 2004 & -0.195 & -0.099 & -0.087 & & & \\
\hline \multirow[t]{8}{*}{2,3} & \multirow{4}{*}{$\begin{array}{l}\text { China Heilongjiang } \\
\text { province }\end{array}$} & & 2002 (urban) & 0.088 & NA & & & $x$ & \\
\hline & & & 2002 (rural) & 0.075 & & & & & \\
\hline & & & 2007 (urban) & -0.020 & & & & & \\
\hline & & & 2007 (rural) & 0.027 & & & & & \\
\hline & \multirow{4}{*}{$\begin{array}{l}\text { China Gansu } \\
\text { province }\end{array}$} & & 2002 (urban) & 0.0455 & 0.0854 & 0.0431 & $x$ & & [18] \\
\hline & & & 2002 (rural) & 0.0448 & 0.0810 & 0.0148 & & & \\
\hline & & & 2007 (urban) & 0.0488 & 0.0089 & 0.0351 & & & \\
\hline & & & 2007 (rural) & 0.0086 & 0.2534 & -0.0226 & & & \\
\hline \multirow[t]{2}{*}{4} & \multirow[t]{2}{*}{ Columbia } & & 1984 & -0.009 & NA & & $x$ & $x$ & [14] \\
\hline & & & 1997 & 0.003 & & & & & \\
\hline \multirow[t]{4}{*}{5} & \multirow[t]{4}{*}{ Iran } & & 1984 (urban) & 0.455 & NA & & $x$ & & [19] \\
\hline & & & 1984 (rural) & 0.443 & & & & & \\
\hline & & & 2010 (urban) & 0.446 & & & & & \\
\hline & & & 2010 (rural) & 0.417 & & & & & \\
\hline \multirow[t]{4}{*}{6} & \multirow[t]{4}{*}{ Thailand } & & 2000 & -0.150 & -0.362 & -0.004 & & $x$ & {$[12]$} \\
\hline & & & 2002 & -0.076 & -0.391 & 0.001 & & & \\
\hline & & & 2004 & -0.076 & -0.323 & 0.034 & & & \\
\hline & & & 2006 & -0.045 & & 0.041 & & & \\
\hline \multirow[t]{5}{*}{7,8} & \multirow[t]{5}{*}{ Turkey } & & 2003 & -0.147 & NA & & & $x$ & [15] \\
\hline & & & 2006 & -0.152 & & & & & \\
\hline & & & 2003 & 0.079 & & & $x$ & & [16] \\
\hline & & & 2006 & 0.009 & & & & & \\
\hline & & & 2009 & -0.028 & & & & & \\
\hline \multirow[t]{2}{*}{9} & \multirow[t]{2}{*}{ Vietnam } & & Insured (1999) & $\begin{array}{l}\text { from }(-0.244) \\
\text { to }(-0.065)\end{array}$ & NA & & $x$ & & [13] \\
\hline & & & Uninsured (1999) & $\begin{array}{l}\text { from }(-0.242) \\
\text { to }(-0.173)\end{array}$ & & & & & \\
\hline \multirow[t]{3}{*}{10} & \multirow[t]{3}{*}{ Czech Republic } & 2 & 2007 & -0.084 & NA & & $x$ & & [22] \\
\hline & & & 2008 & -0.125 & & & & & \\
\hline & & & 2009 & -0.114 & & & & & \\
\hline 11 & Estonia & & 2000 & -0.300 & NA & 0.032 & $x$ & & [20] \\
\hline & & & 2007 & -0.379 & & 0.005 & & & \\
\hline 12 & Hungary & & 2005 & -0.220 & NA & & & $x$ & {$[21]$} \\
\hline & & & 2006 & -0.224 & & & & & \\
\hline & & & 2007 & -0.220 & & & & & \\
\hline & & & 2008 & -0.215 & & & & & \\
\hline 13 & Slovakia & & 2001 & -0.170 & NA & 0.020 & & $x$ & [11] \\
\hline & & & 2005 & -0.210 & & -0.010 & & & \\
\hline
\end{tabular}


Table 5 Kakwani index of progressivity in selected publications (Continued)

\begin{tabular}{|c|c|c|c|c|c|c|c|c|c|}
\hline \multirow[t]{2}{*}{14} & Bulgaria & 3 & 1995 & -0.320 & NA & -0.258 & $x$ & & [23] \\
\hline & & & 2001 & -0.396 & & -0.316 & & & \\
\hline \multirow[t]{2}{*}{15} & France & & 2001 & 0.043 & -0.248 & NA & $x$ & & [25] \\
\hline & & & 2004 & 0.046 & -0.254 & & & & \\
\hline \multirow[t]{3}{*}{16} & Ireland & & 1987/1988 & -0.010 & 0.080 & NA & & $x$ & [24] \\
\hline & & & 1999/2000 & -0.100 & 0.060 & & & & \\
\hline & & & $2004 / 2005$ & -0.108 & -0.032 & & & & \\
\hline
\end{tabular}

variable both studies provided similar trends for changes in the Kakwani index in Turkey. Not only did the trends for both China and Iran indicate change towards less progressive OOP payment distribution but they lay outside the range for others. Apart from a significant change in the regressivity of the Kakwani index for the Chinese urban cohort, all other results were found insignificant.

As far as the second group is concerned, none of the studies reached significance in the change to the Kakwani index (Table 2). Among the publications included, Central Eastern European settings prevailed [20-22]. The implementation of formal user fees made OOP health payments most burdensome in Estonia [20]. A similar health policy change cannot be neglected with respect to the Slovak households either [11]. Comparison of the Kakwani index revealed that Hungarian OOP payments were the second most regressive source of healthcare financing across the jurisdictions studied [21]. In the Czech Republic the introduction of formal user fees affected the poorest to the greatest extent in the first year, the situation however improved in the subsequent year. It must be mentioned however that Czech co-payments for General Practitioners (GPs) were comparable to those in Estonia. In the majority of cases across the jurisdictions studied, specialists' fees varied depending upon referral from GPs. Among the protection mechanisms for the most vulnerable, the exemption mechanism prevailed. A ceiling on copayments was introduced in the Czech Republic and Estonia as well as Hungary [20-22].

In similar fashion to the second group, none of the studies in the last group produced significant results regarding changes in the Kakwani index in the period studied. Among the publications included in the third group, there were studies of Bulgarian, Irish and French reforms [23-25]. The results were mixed. In the first case, the introduction of healthcare insurance alongside formal fees for healthcare visits worsened the OOP burden. The trend towards regressivity of OOP spending continued throughout the observation period in Ireland as well [24]. It has to be underlined that the Irish data allowed for the longest follow up. In France, by contrast, the Kakwani index stayed almost unchanged [25].
Although OOP payments remained a positive source of healthcare financing throughout the observation period there, the Kakwani index for VHI remained negative which balanced the progressivity of OOP payments to some extent.

As far as the choice of proxy for the ability to pay is concerned, both household disposable income and household expenditure were utilized so that half of the studies used the first and the other half the second measurement. No clear pattern of impact related to choice on the results could be distinguished.

\section{Discussion}

Among the 16 studies included, a significant health policy impact was only achieved in four cases, and all of these related to the reduction of the OOP burden. Among them were three studies which revealed a change towards progressivity. The remaining one was reported for China and surprisingly indicated a trend towards regressivity of OOP payments. As the Kakwani index for the Chinese study lay outside the range of the others, its results have to be treated with caution.

None of the studies related to the introduction of formal fees for healthcare visits noted a significant impact on OOP payment distribution.

The majority of health policy attempts on the reduction of OOP burden were studied in developing countries. Interestingly enough, publications regarding the consequences of the introduction of formal fees for healthcare visits concerned healthcare reforms conducted in Central Eastern European (CEE) settings.

As far as the first study objective is concerned, the systematic literature review that was performed provided two key valuable insights into the effects of health policies against excessive OOP burden.

First of all, revealed evidence indicated that the reduction of a household financial healthcare burden could not be achieved without adequate involvement of indirect sources of healthcare financing. This was proved with the examples from both Columbia and Bulgaria [14, 23]. In the Columbian case, the health care reform was based on social insurance. Due to a slow uptake in the implementation of the new scheme, the achievement of equal 
distribution of OOP payments was very limited [14]. Seven years after the reform's implementation, as many as $40 \%$ of the eligible poor still did not have healthcare insurance coverage [14]. Additionally, the scope of reimbursement remained very limited to primary care services. In similarity with the Columbian example, a slow uptake of healthcare insurance coverage was noted in Bulgaria [23]. Public sources still constituted only $57 \%$ of total healthcare financing 7 years after the reform took place [26]. Furthermore as many as $25 \%$ of citizens remained uninsured in 2011 and $19 \%$ in 2013 $[27,28]$. It is estimated that up to half of private expenses could be caused by underfunding of the healthcare system from public sources in Bulgaria [29].

Secondly, the reviewed evidence provides some indication that the negative consequences of the households' direct engagement in the healthcare financing could be mitigated with voluntary health insurances (VHI). A notable example in this regard is France. The Kakwani index of OOP payments was positive in both years of the study. The potential explanation for such a result could be the popularization of VHI, the key role of which is to provide reimbursement of user fees. VHI accounted for $13 \%$ of total expenditure on health and covered more than $90 \%$ of the population in 2007 [30]. There are, however, risks involved with reliance on VHI as a key contributor to the healthcare budget. On the one hand, VHI does ensure progressivity of OOP payments. On the other, it is a regressive source of healthcare financing on its own. According to the available studies, socio-demographic differences favoring the welloff among the consumers of VHI prevail in France. In addition to the steady growth of the insurance premium, the scope of VHI's coverage has only broadened to a limited extent. According to the available data, VHI turnover increased by $48 \%$ while benefits only broadened by $32 \%$ in the same period of time [30]. Having acknowledged the access issue, the French government launched numerous solutions for poor groups of society, including public complementary health insurance (CMU) and a voucher scheme (ACS) for those who cannot afford VHI (Table 4). It remains to be seen whether these solutions are effective enough to improve equity in access to the healthcare sector.

The Irish example could provide additional insight into how to overcome economic barriers for poor households when discussing the importance of VHI for the reduction of the OOP burden [31]. According to legal regulations, Irish insurers must not vary coverage or premium by age or gender, nor current or prospective state of health or any other risk factor. There are additional principles such as open enrollment, lifetime cover and regulated premiums which minimize access barriers for the least disadvantaged. Obviously, it is not possible to conclude whether these particular features of the Irish system made the Kakwani index of VHI progressive or almost proportional in the period studied. The so called community rating system certainly has pros and cons. On the one hand, it ensures that unhealthy poor individuals are not faced with catastrophic OOPs. On the other, it does not prevent the healthy poor from subsidizing the health costs of others. The Vietnamese example indicates that the overall balance could be positive [32]. If the financial contribution is simply lower than the potential costs of healthcare otherwise purchased on the private market, VHI can reduce the financial burden on poor households. The Vietnamese results revealed that the distribution of OOP payments was more equitable among those who purchased VHI than the rest of the population.

As far as the second research objective is concerned, the conducted literature review addressed the question as to whether the implementation of any form of OOPs may impact negatively upon fairness in financial contribution. Oddly enough, it revealed that the introduction of formal user fees for healthcare visits did not affect the distribution of OOP health expenses to a significant extent. Nevertheless, the majority of jurisdictions subsequently abolished them anyway. It is however not surprising, if one takes into account the fact that four out of five jurisdictions did introduce formal user fees without any protective mechanism against excessive direct healthcare expenditures. In Hungary, the system for privileged groups became even more restrictive prior to the implementation of formal fees. The right to free of charge access to drugs was replaced by a monthly personal budget of up to HUF 12,000 (€45) to cover private expenses associated with the treatment of chronic diseases, along with HUF $6000(€ 24)$ for acute problems [33]. Expenses above these limits were to be covered out of pocket.

The Czech Republic was the only jurisdiction which actually introduced a ceiling for formal user fees'. Even there however, there were some challenges with implementation. Firstly a cap of 200 EUR was established for expenses related to doctor visits and drug costs. It turned out however that only $0.2 \%$ of those insured exceeded this limit in 2008. To adjust further for the real burden of OOP payments, the cap was limited to 100 EUR for the most vulnerable groups of patients in 2009 [34]. Although it is unclear how the introduction of the ceiling translated into a reduction in the burden of OOPs, it has to be admitted that the Kakwani index measured after the introduction of formal fees was the lowest in the Czech Republic across all five jurisdictions included in the systematic review which did introduce formal user fees. Ceilings on spending on OOPs exist in both France and Ireland as well. Interestingly enough, in 
each of these jurisdictions the Kakwani index was higher compared to any of the five countries which launched formal fees during the observation period.

The importance of exemption from direct healthcare payments for the least disadvantaged can be illustrated by the Irish example. In principle, the poorest were entitled to free of charge healthcare. The so called system of medical cards covered roughly $30 \%$ of the population [35, 36]. From 2001 until 2009, eligibility was broadened to those above 70 years of age irrespective of income as well. Before this happened, due to legal changes a decline in the number of medical card holders (roughly 94,000) was observed. According to some experts, this decrease was actually responsible for the Kakwani index being in favor of the better off in 2004/2005 [24].

Although productive in the number of conclusions drawn, the systematic review conducted was not free from limitations. There are at least four reasons which warrant some caution in the ability to generalize the findings across jurisdictions. Firstly, the scope of the study did not include any other measures of OOP distribution such as fairness in financial contribution (FFC) or catastrophic health care expenditures. Secondly, it excluded publications which presented Kakwani index less often than at two separate time points. Thirdly, only English written papers published in the last 10 years were reviewed. Fourthly, due to the variety of the local settings across included studies, some caution should be executed while interpreting the results of the conducted systematic review. The political, social and economic circumstances under which a given health policy was implemented, inevitably had some impact on its outcome. Hence the generalizability of our study findings is limited to some extent.

Finally, there are various forms of direct patients' participation in healthcare financing such as coinsurance, copayments or deductibles. Although they differ from each other in terms of the division of the financial responsibilities between patient and healthcare service provider, the scope of this particular systematic review was limited to the study of the overall distribution of OOP payments across income groups only. Hence, potential differences in the impact of various forms of household engagement in the healthcare financing on the equity in the healthcare financing could not be distinguished.

Regardless of the above mentioned limitations, the systematic review that was carried out provides a couple of key recommendations for both researchers and health policy makers interested in the analysis of the OOP burden in the healthcare sector.

Turning firstly to future researchers analyzing equity of healthcare financing, the conducted systematic literature review underlines how crucial it is to understand the context in which the Kakwani index is measured. This can be illustrated with examples from China and Iran [17-19]. Irrespective of reforms, direct household spending still remained a key source of healthcare financing there. The observed progressive distribution of OOP payments is driven mainly by the healthcare consumption of the richest, who purchase healthcare services on the private market. Poor groups cannot afford it and do not seek medical help. Hence the positive value of the Kakwani index should be interpreted as an issue with access to the healthcare system rather than equitable distribution favoring the least disadvantaged.

The Canadian study is another interesting example of the importance of the context of the analysis of progressivity of OOP payments [10]. In fact, the improvement of the Kakwani index arose from the decline in public subsidy for high-income seniors rather than an increased benefit for low-income non-seniors. Namely, as a consequence of a change from age-based to income-based subsidies, there was a reduction of public coverage for high-income seniors. It was estimated that the public subsidy for senior households with incomes above the 95th percentile was reduced from approximately $65 \%$ to less than $20 \%$ of their drug expenses [10]. The change towards a more progressive distribution of OOP spending was not accompanied, however, by any redistribution effects to the benefit of low-income households. Hence the study of the Kakwani index of progressivity alone does not provide a full picture. In order to understand the consequences of each policy change, studies on the utilization patterns of healthcare services have to be undertaken as well.

Turning secondly to health policy makers evaluating alternative attempts to reduce the OOP burden, the conducted systematic literature review indicates that to achieve progressivity in health financing the share of regressive sources, particularly out-of-pocket payments, can be reduced or replaced by adequate funds from indirect financial sources. The study from Thailand provides a very inspiring example in this regard. The introduction of a tax-funded health insurance scheme provided coverage for $75 \%$ of the population who were previously not entitled to any other Benefit Schemes. The increase in financing from direct taxes (from $18 \%$ in 2000 to $24.5 \%$ in 2006) and social health insurance (SHI) contribution (from $5.3 \%$ in 2000 to $8.9 \%$ in 2004) lead to the reduction of the OOP burden (from $33.7 \%$ in 2000 to $23.2 \%$ in 2006) and an improvement of the Kakwani index from -0.150 to -0.045 [12].

Taking the health policy makers' perspective into account, the performed systematic review indicates clearly that a universal system based on health tax or SHI 
contribution needs to be implementable first to effectively improve fairness in financial contribution.

The example from Bulgaria illustrates that too slow an uptake of SHI did not manage to diminish the OOP burden throughout the observation period. Instead of being a tool to navigate the demand towards more appropriate channels, direct healthcare expenditures still remained a very important source of healthcare financing. In 2009 formal payments alone accounted for $35.3 \%$ of total health expenditure in Bulgaria [37].

As an alternative solution to the increase of healthcare financing from indirect sources, health policy makers can turn to the introduction of private healthcare insurance as well. Indeed the evidence available provides some support for such a solution. However, it should be underlined that VHI acts against the key principle of user fees, which is to increase awareness regarding the real cost of specific treatments. Cost-sharing mechanisms aim to ensure optimal allocation of available healthcare resources by directing demand towards the most effective healthcare services designed for specific health problems as well. Thus, the elevation of patients' fees might be counterproductive towards allocative efficiency of the healthcare system. Some jurisdictions have initiated actions to mitigate such risks. The French authorities introduced an additional fee for patients who choose to divert their treatment path from standard procedures. Moreover, some financial incentives have been introduced for insurance companies not to cover certain patients' fees within VHI [30]. In similarity with the French example, the Irish authorities introduced specific regulations regarding voluntary healthcare insurance [36]. While hospital fees are mainly covered by private health insurance, GP fees are only reimbursed by VHI to a certain extent.

If the health policy objective is to improve fairness in financial contribution by the elimination of informal fees, the review of available literature indicates that there is little chance of improving progressivity after the introduction of formal cost sharing. The Hungarian example could provide interesting learning in this regard. After the implementation of formal fees, the regressivity pattern of OOP payments may still remain a challenge in Hungary. Some reduction of inequity in the distribution of informal gratuities indeed took place (the Kakwani index changed from -0.20 to -0.12 ), however the formal fees turned out to be a regressive source of healthcare financing (the Kakwani index decreased from -0.004 to $-0.096)$ [20]. Hence to avoid further regressivity of OOP payments with cost sharing schemes, protection against the excessive burden of OOPs for the least disadvantaged groups of society have to be thoroughly considered.

\section{Conclusions}

Although limited to only 16 examples, the literature review that was carried out provides an interesting insight into real life examples regarding the impact of different health policies on the distribution of direct healthcare expenditures. Achieving fairness in financial contribution with respect to OOP health payments is not an easy challenge. A healthcare financing system is built on several interconnected pillars, and a healthcare reform focused on one of them will never be successful unless the impact on others is taken into consideration. There is still a lot of room for improvement among both the most and least developed countries. No "one size fits all" solution has been discovered. Nevertheless, learning from the successes and failures of others must be regarded as an important lesson prior to any healthcare reform implementation.

\section{Abbreviations \\ C: Concentration index; G: Gini coefficient; GP: General practitioner; OOPs: Out of pocket payments; PRISMA: Preferred Reporting Items for Systematic Reviews and Meta-Analyses; SHI: Social health insurance; VHI: Voluntary health insurance; WHO: World Health Organization}

\section{Acknowledgements}

No acknowledgements to be made.

\section{Funding}

No funding has been received for this research.

\section{Authors' contributions}

KK has conducted the study concept and prepared a final manuscript. Both KK and MK have conducted the review of publications separately. The contribution of both authors is following: KK- $80 \%$, MK- $20 \%$. Both authors read and approved the final manuscript.

\section{Competing interests}

The authors declare that they have no competing interests.

Ethics approval and consent to participate

No ethical approval was required for the conduct of this study. No patient contest was needed either. No consents required.

\section{Author details}

${ }^{1}$ Health Economics Department, Collegium Medicum Bydgoszcz, Sandomierska 16, 85-630 Bydgoszcz, Poland. ²Pharmacoeconomics Department, Medical University of Warsaw, Żwirki i Wigury 81, 02-091 Warsaw, Poland

Received: 29 January 2016 Accepted: 1 September 2016 Published online: 15 September 2016

\section{References}

1. WHO. The world health report 2000. Health systems: improving performance. World Health Organization: Geneva; 2000. Available at: http://www.who.int/ whr/2000/en. Accessed 10.12.14

2. OECD Health Data, OECD; 2014. Available at: www.oecd.org/els/healthsystems/health-data.htm. Accessed 10.12.14

3. Daniels N, Bryant J, Castano RA, Dantes OG, Khan KS, Pannarunothai S. Benchmarks of fairness for health care reform: a policy tool for developing countries. Bull World Health Organ. 2000;78:740-50.

4. Thomson S, Võrk A, Habicht T, Rooväli L, Evetovits T, et al. Responding to the challenge of financial sustainability in Estonia's health system, World Health Organization: Geneva; 2010. Available at: http://www.euro.who.int/ data/assets/pdf_file/0006/97701/E93445.pdf. Accessed 26.12.14 
5. OECD. Out-of-pocket expenditureon health, Health: Key Tables from OECD, No. 5, OECD; 2014. Available at: 10.1787/oopexphtl-table2014-1-en. Accessed 28.12.14

6. Newhouse JP. The Insurance Experimental Group. Free for all? Lessons from the RAND Health Insurance Experiment. Cambridge: Harvard University Press; 1993.

7. Wagstaff A, van Doorslaer E, Calonge S, Christiansen T, Gerfin M, et al. Equity in the finance of health care: some international comparisons. J Health Econ. 1992;11(4):361-87.

8. PRISMA statement. http://www.prisma-statement.org/ Accessed 16.02.16

9. Yu CP, Whynes DK, Sach TH. Equity in health care financing: the case of Malaysia. Int J Equity Health. 2008;7:15.

10. Hanley GE, Morgan S, Hurley J, van Doorslaer E. Distributional consequences of the transition from age-based to income-based prescription drug coverage in British Columbia, Canada. Health Econ. 2008;17(12):1379-92.

11. Kiss S. Equity in Health Care Finance in Slovakia - the Impact of the Reform, University Rotterdam, Erasmus; 2007. Available at: http://static.etrend.sk/ uploads/tx_media/blogy/169/STEFAN-KISS-EQUITY-IN-HEALTH-CAREFINANCE-THESIS-FINAL.pdf. Accessed 29.12.14

12. Limwattananon $S$, Vongmongkol $V$, Prakongsai $P$, Patcharanarumol W, Hanson K, Tangcharoensathien V, et al. The equity impact of Universal Coverage: health care finance, catastrophic health expenditure, utilization and government subsidies in Thailand, London: Consortium for Research on Equitable Health Systems; 2011. Available at: http://www.crehs.Ishtm.ac.uk/ thai_biafia_19jul.pdf. Accessed 29.12.14

13. Shehzad I Ali. Measuring the impact of Voluntary Health Insurance on out of pocket costs and socioeconomic-related inequality: methodological challenges and potential solutions with an application to Vietnam, York: University of York; 2009. Available at: etheses.whiterose.ac.uk/855. Accessed 29.12.14

14. Castano RA, Arbelaez JJ, Giedion UB, Morales LG. Equitable financing, outof-pocket payments and the role of health care reform in Colombia. Health Policy Plan. 2002;17 Suppl:5-11.

15. Özlem Göçmez. Out of Pocket Payments for Healthcare in Turkey and Equity in Financing, 2003-2006, Rotterdam: Erasmus University; 2010. Available at: thesis.eur.nl/pub/.../Ozlem\%20Gocmez-thesisEU.doc Accessed 31.12.14

16. Yardim MS, Cilingiroglu N, Yardim N. Financial protection in health in Turkey: the effects of the Health Transformation Programme. Health Policy Plan. 2014:29(2):177-92.

17. Chen M, Zhao Y, Si L. Who pays for health care in China? The case of Heilongjiang Province. PLoS One. 2014;9(10):1-11.

18. Chen M, Chen W, Zhao Y. New evidence on financing equity in China's health care reform-a case study on Gansu province, China. BMC Health Serv Res. 2012;12:466

19. Zare H, Trujillo AJ, Driessen J, Ghasemi M, Gallego G. Health inequalities and development plans in Iran; an analysis of the past three decades (1984-2010). Int J Equity Health. 2001;13:42-54.

20. Võrk A, Saluse J, Habicht J. Income-related inequality in health care financing and utilization in Estonia 2000-2007. Health Financing Technical Report. World Health Organization: Geneva; 2009. Available at: http://ee. euro.who.int/E92592.pdf. Accessed 05.01.15

21. Baji P, Pavlova M, Gulácsi L, Groot W. Changes in equity in out-of-pocket payments during the period of health care reforms: evidence from Hungary. Int J Equity Health. 2012;11:36.

22. KrůtilováV. Cost sharing of patients for health care-forms, extent, impacts, Brno: Masaryk University; 2013. Available at: http://theses.cz/id/jzszkk/?furl= \%2Fid\%2Fjzszkk\%2F;so=nx;lang=en. Accessed 29.12.14

23. Markova N. How Does the Introduction of Health Insurance Change the Equity in the Health Care Provision in Bulgaria?International Monetary Fund No 06/285; Available at: https://www.imf.org/external/pubs/ft/wp/2006/ wp06285.pdf. Accessed 05.01.15

24. Smith S. Equity in Irish health care financing: measurement issues. Health Econ Policy Law. 2010;5(2):149-69.

25. Dukhan Y, Korachais C, Mathonnat J. Financial burden of health payments in France: 1995-2006, Discussion Paper 06/2010, Geneva: World Health Organization; 2010. Available at: http://www.who.int/health_financing/ documents/cov-dp_e_10_06-frp_fra/en/ Accessed 06.01.15

26. Atanasova $E_{\text {, et }}$ al. What have 10 years of health insurance reforms brought about in Bulgaria? Re-appraising the Health Insurance Act of 1998. Health Policy. 2011;102:263-9.
27. Atanasova E, Pavlova M, Moutafova E, Rechel B, Groot W. Out-of-pocket payments for health care services in Bulgaria: financial burden and barrier to access. Eur J Public Health. 2013;23(6):916-22.

28. Novinite. 19\% of Bulgarians Paid No Health Insurance Contributions in 2013, Novinite; 2014. Available at. http://www.novinite.com/articles/ 163462/19+of+Bulgarians+Paid+No+Health+Insurance+Contributions+in +2013. Accessed 06.02.15

29. Dimova A, Rohova M, Moutafova E, Atanasova E, Koeva S, et al. Bulgaria: Health system review. Health Systems in Transition, Copenhagen: European Observatory on Health Systems and Policies, 2012;14(3):1-186

30. Chevreul K, Durand-Zaleski I, Bahrami S, Hernández-Quevedo C, Mladovsky P. France: Health system review. Health Systems in Transition, Copenhagen: European Observatory on Health Systems and Policies, 2010; 12(6): 1-291

31. Thomson S. Mossialos E. Private health insurance and access to health care in the European Union, Copenhagen: European Observatory on Health Systems and Policies, Newsletter of the European Observatory on Health Systems and Policies 2004; 6(1) Available at: http://www.Ise. ac.uk/LSEHealthAndSocialCare/pdf/euroObserver/ObsVol6no1.pdf. Accessed 06.02.15.

32. Gottret $P$, Schieber $G$, Waters $H$. Good practice in health financing: lessons from reforms in low and middle-income countries, The International Bank for Reconstruction and Development

33. Gaál P, Szigeti S, Csere M, Gaskins M, Panteli D. Hungary: Health system review. Health Systems in Transition, Copenhagen: European Observatory on Health Systems and Policies 2011; 13(5):1-266.

34. Bryndova L, Pavlokova K, Roubal T, Rokosova M, Gaskins M, i van Ginneken E. (2009). Czech Republic: Health system review, Health Systems in Transition. European Observatory on Health Systems and Policies 11(1)

35. McDaid D, Wiley M, Maresso A, Mossialos E. Ireland: Health system review. Health Systems in Transition, Copenhagen: European Observatory on Health Systems and Policies 2009;11(4): 1-268

36. Layte R, Nolan B. Equity in the utilization of health care in Ireland. The Economic and Social Review. 2004;35(2):111-34

37. Atanasova E, Moutafova E, Kostadinova T, Pavlova M. Patient payments and the problems in medical services provision in Bulgaria. ZdrowiePubliczne iZarządzanie. 2010;VII(1):48-9.

38. Tatar M, Mollahaliloğlu S, Şahin B, Aydın S, Maresso A, Hernández Quevedo C. Turkey: Health system review. Health Systems in Transition, Copenhagen: European Observatory on Health Systems and Policies 2011, 13(6):1-186

39. Atun R, Aydın S, Chakraborty S, Sümer S, Aran M, Gürol I, Nazlıoğlu S, Ozgülcü S, Aydoğan U, Ayar B, Dilmen U, Akdağ R. Universal health coverage in Turkey: enhancement of equity. Lancet. 2013;382(9886):65-99.

40. Lai T, Habicht T, Kahur K, Reinap M, Kiivet R, van Ginneken E. Estonia: health system review. Health Systems in Transition, Copenhagen: European Observatory on Health Systems and Policies 2013;15(6):1-196

41. Habicht J, Xu K, Couffinhal A, Kutzin J. Detecting changes in financial protection: creating evidence for policy in Estonia. Health Policy Plan. 2006; 21(6):421-31.

42. Szalay T, Pažitný P, Szalayová A, Frisová S, Morvay K, et al. Slovakia: Health system review. Health Systems in Transition, Copenhagen: European Observatory on Health Systems and Policies 2011; 13(2):1-200 